\title{
PENGARUH MOTIVASI DAN PENGALAMAN KERJA TERHADAP PRODUKTIVITAS KERJA KARYAWAN PT. SUZUKI DIANA MOTOR CABANG PALOPO
}

\author{
Haedar ${ }^{1}$ \\ Suandi Putra Syamsuddin²
}

No. HP $081342701659^{1}$

\section{ABSTRAK}

Penelitian ini bertujuan untuk mengetahui pengaruh motivasi dan pengalaman kerja terhadap produktivitas kerja karyawan pada PT. Suzuki Diana Motor Cabang Palopo.

Metode yang digunakan adalah metode analistis regresi linier berganda. Data yang digunakan adalah data primer dan data sekunder yang dihasilkan dari penelitian lapangan dan studi kepustakaan.

Hasil analisis regresi berganda penelitian ini membuktikan bahwa motivasi dan pengalaman kerja berpengaruh terhadap produktivitas kerja karyawan pada PT. Suzuki Diana Motor Cabang Palopo dengan nilai koefisiensi korelasi pada output SPSS sebesar 0,919.

Dengan hasil analisa yang telah dilakukan penelitian ini menyimpulkan bahwa terbukti terdapat pengaruh yang sangat kuat dan signifikan antara motivasi dan pengalaman terhadap produktivitas kerja karyawan pada PT. Suzuki Diana Motor Cabang Palopo..

Hasil analisis menunjukkan motivasi berpengaruh positif terhadap produktivitas kerja karyawan. Pengalaman kerja berpengaruh positif terhadap produktivitas kerja karyawan.

\section{Kata Kunci: Motivasi dan pengalaman kerja berpengaruh Produktivitas Kerja Karyawan.}

\section{PENDAHULUAN}

Kualitas sumber daya manusia sebagai tenaga kerja merupakan modal dasar dalam masa pembangunan. Tenaga kerja yang berkualitas akan menghasilkan suatu hasil kerja yang optimal sesuai dengan target kerjanya. Manusia sebagai tenaga kerja atau karyawan merupakan sumber daya yang penting bagi perusahaan, karena mereka mempunyai bakat, tenaga dan kreativitas yang sangat dan dibutuhkan oleh perusahaan untuk mencapai tujuannya.

Sebaliknya sumber daya manusia juga mempunyai berbagai macam kebutuhan yang ingin dipenuhinya. Keinginan para karyawan untuk memenuhi kebutuhan inilah yang dapat memotivasi seseorang untuk melakukan sesuatu termasuk untuk melakukan pekerjaan atau bekerja.

Dalam suatu sistem operasi perusahaan, potensi sumber daya manusia pada hakekatnya merupakan salah satu modal dan memegang suatu peran yangg paling penting dalam mencapai tujuan perusahaan. Oleh karena itu perusahaan perlu mengelola sumber daya manusia sebaik mungkin. Sebab kunci sukses suatu perusahaan bukan hanya pada keunggulan teknologi dan tersedianya dana saja. Tapi faktor manusia merupakan faktor yang terpenting pula Melalui perencanaan sumber daya manusia yang matang, produktivitas kerja dari tenaga kerja yang sudah ada dapat 
ditingkatkan. Hal ini dapat diwujudkan melalui adanya penyesuaian. Seperti peningkatan motivasi dan pengalaman kerja yang baik. Sehingga setiap karyawan dapat menghasilkan sesuatu yang berkaitan langsung dengan kepentingan organisasi.

Motivasi dan pengalaman kerja yang baik dapat juga menunjang keberhasilan suatu perusahaan dalam mencapai tujuannya. Sebab melalui adanya dua faktor tersebut akan menciptakan tingkat produktivitas kerja yang tinggi sehingga menunjang keberhasilan perusahaan. Sebaliknya jika tingkat produktivitas kerja menurun akan menghambat perusahaan tersebut dalam mencapai tujuannya.

Oleh karena itu perkembangan mutu sumber daya manusia semakin penting keberadaannya. Hal ini mengingat bahwa perusahaan yang mempekerjakan sumber daya manusia, menginginkan suatu hasil dan manfaat yang baik dan dapat mengikuti perubahan dan perkembangan yang terjadi dalam perusahaan.

Motivasi dan pengalaman kerja merupakan hal yang berperan penting dalam meningkatkan suatu efektivitas kerja. Karena orang yang mempunyai motivasi dan pengalaman kerja yang tinggi akan berusaha dengan sekuat tenaga supaya pekerjaanya dapat berhasil dengan sebaik-baiknya, akan membentuk suatu peningkatan produktivitas kerja.

$\begin{array}{rrr}\text { Setiap } & \text { perusahaan } & \text { selalu } \\ \text { menginginkan produktivitas dari } & \text { setiap }\end{array}$ karyawannya meningkat. Untuk mencapai hal tersebut, perusahaan harus memberikan motivasi yang baik kepada seluruh karyawannya agar dapat mencapai prestasi kerja dan meningkatkan produktivitas. Dengan ditambah suatu pengalaman kerja yang dimiliki oleh para karyawannya, akan memberikan suatu hubungan yang besar dalam upaya mencapai tingkat produktivitas.

Dalam melakukan usaha meningkatkan produktivitas kerja ini, PT. Suzuki Diana Motor Cabang Palopo telah menetapkan beberapa upaya yang bertujuan untuk memotivasi kerja para karyawannya. Adapun upaya tersebut dengan memberikan beberapa fasilitas-fasilitas kerja yang sangat menunjang dalam meningkatkan produktivitas kepada seluruh karyawanya.

\section{METODE PENELITIAN}

Penelitian ini dilaksanakan di PT. Suzuki Diana Motor Cabang palopo. Populasi dalam penelitian ini adalah seluruh karyawan PT.Suzuki Diana Motor Cabang Palopo yang jumlahnya sebanyak 16 karyawan sekaligus dijadikan sebagai sampel. Jenis dan sumber data yang digunakan yaitu data primer dan data sekunder. Metode pengumpulan data terdiri dari wawancara, kuisioner, dan observasi.

\section{Metode Analisis Data}

Untuk mengetahui pengaruh antara variabel dalam penelitian ini digunakan alat regresi linear berganda. Regresi menunjukkan hubungan antara variabel-variabel yang satu dengan variabel yang lain dimana variabel 
yang satu mempengaruhi variabel yang lain. Adapun rumus regresi berganda (Supranto, 2001) adalah:

$$
\mathrm{Y}=\mathrm{a}+\mathrm{b}_{1} \mathrm{x}_{1}+\mathrm{b}_{2} \mathrm{x}_{2}+\mathrm{e}
$$

Keterangan:

$Y$ : Produktivitas kerja karyawan

$\mathrm{X}_{1}$ : Motivasi

$\mathrm{X}_{2}$ : Pengalaman kerja

$b_{1}$ : Koefisien regresi motivasi

$b_{2}$ : Koefisien regresi pengalaman kerja

a : Konstanta

e : Variabel pengganggu (tak dihitung)

\section{HASIL PENELITIAN DAN PEMBAHASAN}

Hasil pengolahan data dengan SPSS versi 20,0 didapatkan persamaan regresi :

$Y=-2,900+0,837 X_{1}+0,366 X_{2}$

Hasil dari analisis tersebut dapat diinterpretasikan sebagai berikut:

1. Variabel pengalaman kerja dan motivasi mempunyai arah koefisien yang bertanda positif terhadap produktivitas kerja karyawan.

2. Nilai a (konstanta) $-2,900$ artinya bahwa apabila tidak ada variable pengalaman kerja $X_{1}$ dan motivasi $X_{2}$ atau sama dengan nol maka produktivitas kerja karyawan akan turun sebesar -2,900.

3. Koefisien pengalaman kerja memberikan nilai sebesar 0,837 yang berarti bahwa jika pengalaman kerja semakin baik dengan asumsi variabel lain tetap maka produktivitas kerja karyawan akan mengalami peningkatan sebesar 0,837.
4. Koefisien motivasi memberikan nilai sebesar 0,366 yang berarti bahwa setiap kenaikan variabel motivasi sebesar satu satuan engan asumsi variabel pengalaman kerja tetap maka produktivitas kerja karyawan akan mengalami peningkatan sebesar 0,366.

\section{Pengujian Hipotesis}

Untuk menguji tingkat hubungan dari variabel-variabel independen $\left(X_{1}\right.$, dan $\left.X_{2}\right)$ terhadap varabel dependen $(Y)$ digunakan uji t dan uji F. Uji t digunakan untuk menguji koefisien regresi secara individual, uji $F$ digunakan untuk menguji koefisien regresi secara serempak.

\section{Uji F ( Pengujian hipotesis secara} simultan)

Untuk menguji pengaruh variabel bebas secara bersama-sama diuji dengan menggunakan uji F. Hasil perhitungan regresi secara simultan diperoleh sebaga berikut: 


\section{Tabel 1}

Hasil Analisis Regresi Berganda

ANOVA $^{\mathrm{a}}$

\begin{tabular}{|rl|r|r|r|r|r|}
\hline Model & & Sum of & \multicolumn{1}{|c|}{ df } & \multicolumn{1}{c|}{ Mean } & F & Sig. \\
& & Squares & & Square & & \\
\hline \multirow{2}{*}{1} & Regression & 52.321 & 2 & 26.160 & 35.365 & $.000^{\mathrm{b}}$ \\
& Residual & 9.617 & 13 & .740 & & \\
& Total & 61.938 & 15 & & & \\
\hline
\end{tabular}

a. Dependent Variable: Produktivitas Kerja Karyawan

b. redictors: (Constant), Motivasi, Pengalaman Kerja

Pengujian pengaruh variabel bebas secara bersama-sama terhadap variabel terikatnya dilakukan dengan menggunakan uji F. Hasil perhitungan statistik menunjukkan nilai $F$ hitung $=35,365$ dengan signifikansi $0,000^{b}$. Dengan menggunakan batas signifikansi 0,05, maka diperoleh nilai signifikansi tersebut lebih kecil dari 0,05. Hal ini berarti bahwa hipotesis yang menyatakan bahwa secara simultan variabel pengalaman kerja dan motivasi mempunyai pengaruh terhadap produktivitas kerja karyawan.

\section{Koefisien Determinasi $\left(\mathbf{R}^{2}\right)$}

Koefisien determinasi merupakan besaran yang menunjukkan besarnya variasi variabel dependen yang dapat dijelaskan oleh variable independennya. Dengan kata lain, koefisien determinasi ini digunakan untuk mengukur seberapa jauh variable-variabel bebas dalam menerangkan variabel terikatnya. Nilai koefisien determinasi ditentukan dengan nilai adjusted $R$ square sebagaimana dapat dilihat pada tabel 2 berikut:

Tabel 2

\section{Model SummKoefisien Determiasi}

\begin{tabular}{|c|c|c|c|c|c|c|c|}
\hline \multirow[t]{2}{*}{ Model } & \multirow[t]{2}{*}{$\mathrm{R}$} & \multirow[t]{2}{*}{ R Square } & \multirow{2}{*}{$\begin{array}{l}\text { Adjusted R } \\
\text { Square }\end{array}$} & \multirow{2}{*}{$\begin{array}{l}\text { Std. Error of } \\
\text { the Estimate }\end{array}$} & \multicolumn{3}{|c|}{ Change Statistics } \\
\hline & & & & & $\begin{array}{c}\text { R Square } \\
\text { Change }\end{array}$ & $\begin{array}{c}\mathrm{F} \\
\text { Change }\end{array}$ & $\mathrm{df1}$ \\
\hline 1 & $.919^{\mathrm{a}}$ & .845 & .821 & .86008 & .845 & 35.365 & 2 \\
\hline
\end{tabular}

Hasil perhitungan regresi linier berganda diketahui bahwa hubungan antara variabel pengalaman kerja dan motivasi terhadap produktivitas kerja karyawan PT. Suzuki Diana Motor Cabang Palopo adalah sangat kuat yaitu $R=0,919$. Hal ini hubungan antara pengalaman kerja dan motivasi terhadap produktivitas kerja karyawan PT. Suzuki Diana Motor Cabang Palopo adalah sangat kuat dan positif. 
R Square sebesar 0,845 berarti $84,5 \%$ variasi variabel produktivitas kerja dapat dijelaskan oleh variabel pengalaman kerja dan motivasi, sedangkan sisanya sebesar $15,5 \%$ diterangkan oleh variabel lain yang tidak diajukan dalam penelitian ini.

\section{Uji t ( Uji Hipotesis Secara Parsial )}

Hipotesis dalam penelitian ini diuji kebenarannya dengan menggunakan uji parsial. Pengujian dilakukan dengan melihat taraf signifikansi (pvalue), jika taraf signifikansi yang dihasilkan dari perhitungan di bawah 0,05 maka hipotesis diterima, sebaliknya jika taraf signifikansi hasil hitung lebih besar dari 0,05 maka hipotesis ditolak.

\section{Tabel 3 Hasil Uji t Secara Parsial}

\begin{tabular}{|l|c|c|}
\hline Variabel Bebas & t hitung & Sig. t \\
\hline Motivasi (X1) & 3,352 & 0.005 \\
\hline $\begin{array}{l}\text { Pengalaman } \\
\text { kerja (X2) }\end{array}$ & 7,653 & 0.000 \\
\hline
\end{tabular}

\section{Sumber: Lampiran output SPSS}

\section{Uji Hipotesis 1 ( H1 )}

Perumusan hipotesis:

Ho : $\quad \beta i=0$ tidak ada pengaruh positif antara pengalaman kerja dengan kinerja karyawan.

$\mathrm{Ha}$ : $\quad \beta \mathrm{i}>0$ terdapat pengaruh positif antara pengalaman kerja dengan kinerja karyawan.

Dari tabel 3 terlihat bahwa hasil pengujian hipotesis motivasi menunjukkan nilai $\mathrm{t}$ hitung sebesar 3.352 dengan taraf signifikansi 0,005. Taraf signifikansi tersebut lebih sama dengan alpa 0,05, yang berarti bahwa hipotesis dalam penelitian ini menerima $\mathrm{Ha}$ dan menolak Ho. Dengan demikian dapat berarti bahwa hipotesis $\mathrm{H} 1$ “ motivasi mempunyai pengaruh positif terhadap Kinerja karyawan “ diterima.

Uji Hipotesis 2 ( H2 )

Perumusan hipotesis:

Ho: $\quad \beta i=0$ tidak ada pengaruh positif antara motivasi dengan kinerja karyawan.

$\mathrm{Ha}: \quad \beta \mathrm{i}>0$ terdapat pengaruh positif antara motivasi dengan kinerja karyawan.

Dari tabel 3 terlihat bahwa hasil pengujian hipotesis motivasi menunjukkan nilai $t$ hitung sebesar 7.653 dengan taraf signifikansi 0,000. Taraf signifikansi hasil sebesar 0,005 tersebut lebih kecil dari alpa 0,05, yang berarti bahwa hipotesis dalam penelitian ini menerima $\mathrm{Ha}$ dan menolak $\mathrm{Ho}$. Dengan demikian dapat berarti bahwa hipotesis H2 " Motivasi berpengaruh positif terhadap Kinerja karyawan “ diterima.

\section{Pembahasan Hasil Penelitian}

1. Pengaruh motivasi terhadap Produktivitas Kerja Karyawan

Hasil pengujian hipotesis $\left(\mathrm{H}_{1}\right)$ telah membuktikan terdapat pengaruh antara pengalaman kerja terhadap produktivitas kerja karyawan. Melalui hasil perhitungan yang telah dilakukan diperoleh nilai $\mathrm{t}$ hitung sebesar 3.352 dengan taraf signifikansi hasil sebesar 0,005 tersebut sama dengan alpa 0,05, dengan demikian $\mathrm{Ha}$ diterima dan $\mathrm{Ho}$ ditolak. Pengujian ini secara statistik membuktikan bahwa pengalaman kerja berpengaruh positif terhadap produktivitas kerja karyawan, artinya 
bahwa ada pengaruh antara variabel pengalaman kerja terhadap produktivitas kerja karyawan di PT. Suzuki Diana Motor Cabang Palopo.

2. Pengaruh pengalaman kerja terhadap Produktivitas Kerja Karyawan

Hasil pengujian hipotesis $\left(\mathrm{H}_{2}\right)$ telah membuktikan terdapat pengaruh antara motivasi terhadap produktivitas kerja karyawan. Melalui hasil perhitungan yang telah dilakukan diperoleh nilai t hitung sebesar 7.653 dengan taraf signifikansi hasil sebesar 0,000 tersebut sama dengan 0,05 , yang berarti bahwa hipotesis dalam penelitian ini menerima $\mathrm{Ha}$ dan menolak $\mathrm{Ho}$. Pengujian ini secara statistik membuktikan bahwa motivasi berpengaruh positif terhadap produktivitas kerja karyawan. Artinya bahwa ada pengaruh antara variabel motivasi terhadap produktivitas kerja karyawan di PT. Suzuki Diana Motor Cabang Palopo.

\section{SIMPULAN}

1. Hasil pengujian hipotesis telah membuktikan terdapat pengaruh antara motivasi dengan produktivitas kerja karyawan. Pengujian membuktikan bahwa motivasi memiliki pengaruh positif terhadap produktivitas kerja karyawan. Dilihat dari perhitungan yang telah dilakukan diperoleh nilai koefisien sebesar 0,130 dan nilai $t$ hitung sebesar 3,352 dengan nilai signifikansi sebesar 0,005 tersebut lebih kecil dari 0,05 dengan demikian Ha diterima dan Ho ditolak. Hal ini mendukung penelitian yang dilakukan oleh penelitian menurut Rosari (2005) bahwa motivasi pada dasarnya menekankan untuk menghargai tujuan individu sehingga nantinya para individu akan memiliki keyakinan bahwa kinerja aktual akan melampaui harapan kinerja mereka.

2. Hasil pengujian hipotesis telah membuktikan terdapat pengaruh antara pengalaman kerja dengan produktivitas kerja karyawan. Pengujian membuktikan bahwa pengalaman kerja memiliki pengaruh positif terhadap produktivitas kerja karyawan. Dilihat dari perhitungan yang telah dilakukan diperoleh nilai koefisien sebesar 0,489 dan nilai t hitung sebesar 7.653 dengan taraf signifikansi hasil sebesar 0,000 tersebut lebih kecil dari 0,05 , yang berarti bahwa hipotesis dalam penelitian ini menerima $\mathrm{Ha}$ dan menolak Ho.

3. Pengalaman kerja memiliki pengaruh yang paling kuat terhadap produktivitas kerja karyawan PT.Suzuki Diana Motor Cabang Palopo.

\section{SARAN}

1. Bagi Perusahaan

Hendaknya perusahaan dalam meningkatkan produktivitas kerja karyawan dengan lebih menitikberatkan pada motivasi karyawan, dilihat dari kuesioner yang telah diisi oleh karyawan 
PT.Suzuki Diana Motor Cabang Palopo tersebut diperoleh data bahwa karyawan memiliki motivasi yang tinggi pada pekerjaan yang mereka laksanakan, sehingga dengan perusahaan lebih memotivasi karyawannya misalnya dengan pemberian penghargaan terhadap karyawan yang berprestasi atau kenaikan jabatan akan dapat meningkatkan produktivitas kerja karyawan yang lebih baik lagi.

2. Bagi Penelitian Selanjutnya

Hasil Uji $R^{2}$ menunjukkan masih ada variabel-variabel lain yang harus diperhatikan dalam penelitian ini. Penelitian-penelitian lebih lanjut, hendaknya menambah variabel lain yang dapat mempengaruhi produktivitas kerja karyawan, karena dengan semakin baik kinerja dari karyawan maka akan berpengaruh baik juga bagi perusahaan.
Moekijat, Kamus Manajemen, 1999, hal. 330. Penerbit Mandar Maju, Bandung,

Nugroho Budiyuwono, 2003, hal. 261-269. Pengantar Statistik Ekonomi dan Perusahaan, Edisi Revisi, Jilid 2, Cetakan Pertama, AMP YKPN, Yogyakarta,

Siagian, Sondang, P, 2005. Teori Motivasi kerja dan Aplikasinya. Penerbit PT Rineka Cipta. Jakarta.

Sudarto, Teguh, 2004. Pengaruh Motivasi kerja, Kemampuan, Kepemimpinan, dan Budaya Organisasi terhadap Prestasi Kerja. Disertasi. Universitas Brawijaya. Malang.

Susilo Martoyo, 1987. Prosuktivitas, Penerbit Ghanesa, Jakarta.

\section{DAFTAR PUSTAKA}

Bedjo Siswanto, 2007. Produktivitas dan Penerapan, LSIUP

Djarwanto dan Pangestu Subagyo, 1998, hal. 108. Statistik Induktif, edisi Keempat, Cetakan Keempat, BPFE Yogyakarta.

J. Ravianto, Produktivitas dan Pengukuran, 2006, hal.2. Cetakan I, Lembaga Sarana Informasi Usaha dan Produktivitas, Jakarta,

J. Supranto, 2001. Statistik Teori dan Aplikasi, Edisi keenam Jilid 2, Penerbit Erlangga, Jakarta.

M.Manullang, 2001. Manajemen Personalia, Edisi Revisi, Ghalia Indonesia, 